\title{
Control System for Adjusting the Brightness Level with PWM Technique Using Visual Net Microcontroller-Based
}

\author{
Dedi Setiawan ${ }^{1}$, Ishak ${ }^{2}$, Muhammad Ardiansyah Sembiring ${ }^{3}$ \\ 1, 2 Department of Computer Engineering, STMIK Triguna Dharma, North Sumatera, Indonesia \\ ${ }^{3}$ Department of Information Systems, STMIK Triguna Dharma, North Sumatera, Indonesia \\ ${ }^{1}$ setiawandedi07@gmail.com, ${ }^{2}$ ishaktgd@gmail.com, ${ }^{3}$ adinmantap88@gmail.com
}

\begin{abstract}
A lamp is an artificial source of light produced by channeling electric current through the filament, which then heats up and produces light. Eye health experts believe that the ideal brightness of a lamp depends on ambient light. The rule must ensure that the brightness of the lights must be equivalent to the light around because, in that way, the light from the lights and surroundings will blend, and the eyes do not need to work harder. To overcome the problem, a control system was created by implementing the pulse width modulation (PWM) technique to control the brightness of the lights manually using a visual net application. Utilization of a microcontroller as a control center in controlling the brightness level of the lamp using the type of microcontroller AVR16, by displaying the PWM value on a form, designed on the visual net. Thus, it needed to set the level of light brightness to be ideal in the desired conditions.
\end{abstract}

Keywords-Microcontroller, Visual Net, PWM.

\section{INTRODUCTION}

The lamp is an artificial source of light produced by channeling electric current through the filament, which then heats up and produces light. The glass covering the hot filament prevents air from coming into contact with it so that it will not be damaged immediately by oxidation. Lights are marketed in various forms and available in various voltages, ranging from 1.25 volts to 300 volts. The electrical energy required for incandescent lamps to produce bright light is greater than for other artificial light sources such as fluorescent lamps and light diodes so that gradually, in some countries, the incandescent lamp starts to be limited. Additionally, some use of incandescent lamps, for example, chicken heater and infrared heaters in industrial heating, make more use of the heat generated. Conversely, if the brightness level of the lamp is too much, it will cause eye irritation and permanent eye disease.

Eye health experts believe that the ideal brightness of a lamp depends on the ambient light. The rule must ensure that the brightness of the lamp should be equivalent to the light around. Therefore, the light will blend, and the eyes do not have to work harder. A control system needs to be created by implementing the pulse width modulation (PWM) technique that can control the brightness of the lights manually using a visual net application.
Some researchers have researched the application of PWM with a microcontroller, such as single-phase induction motor voltage control using asymmetric PWM and fuzzy logic transitions by Zigirkas and Kalomiros. A microcontroller-based AC voltage regulator for single-phase induction motors using asymmetric pulse width modulation (PWM) and fuzzy logistics was proposed [1]. Zulkifli, Ramli, and Razali developed ZVS power converters for voltage control with low-cost microcontrollers. Tests on open and closed-loop were applied using Proportional Integral (PI) control to control the Pulse Width Modulation (PWM) signal pattern for the inverter output in hardware trial testing [2]. Single-phase seven-level inverter Pulse Width Modulated (PWM) controls were designed for hardware and singlephase seven-level inverter implementation [3]. Ravindran implemented the microcontroller arm to maximize solar panel power output using the Hill-Climbing Algorithm. The microcontroller controlled the solar panel current with the help of a 12bit ADC sampling frequency of $200 \mathrm{kHz}$ and adjusted the duty cycle of the PWM signal given to the converter gate drive circuit [4]. Xu and Kang designed the PWM speed DC motor drive. The design of a bipolar pulsewidth modulation (PWM) motor speed control system was used in the PIC16F876 microchip as a control system circuit and became the main technology controlling DC motors [5].

An inexpensive didactic module for adding single-phase inverters was published by Silva. It was a one-phase DC-AC converter controlled by a Pulse Width Modulation (PWM) strategy, consisting of software and hardware elements that suggested the users connect the converter to applications on mobile phones [6]. A multi-carrier PWM implementation using TMSthe 320F28335 DSP application for the multicellular single-phase inverter series was released by Guedouani using MATLAB/Simulink and the coding tool for the TMS320F335 floating-point digital signal processor (DSP) [7]. Savkin investigated a real-time drive model activated based on the LUT magnetization curve for educational purposes. The structure of the model for real-time execution in a motion control microcontroller, run under PWM frequencies up to $40 \mathrm{kHz}$ [8] had been optimized. Ceiling fan speed control using pw technique traced by Shivesh consisted of a PIC16F877A microcontroller, a temperature sensor, an ultrasonic sensor, an optocoupler 
circuit, a BLDC motor, and various electronic components to connect the fan speed to PWM [9]. Bolanos-Cerrud studied optimization algorithm for accurate sine wave PWM generation with a microcontroller replacement. The numerical methods and procedures were used in the algorithm to solve numerical obstacles in achieving accurate PWM sine wave frequency generation [10].

Aref examined microcontrollers for MPPT digital control Table PV systems. The SPWM was generated by comparing sinusoidal waves with a variable frequency of sawtooth waves using the Perturb and Observe $(\mathrm{P} \& \mathrm{O})$ method for MPPT control of PV systems [11]. Pimentel investigated HIL-based DC Motor Speed Control, implemented as a physical system handled by IGBT, based on PI control using a microcontroller PWM output [12]. Yener designed a microcontroller-based ECG signal generator using a PWM microcontroller output and experimental ECG data. It appeared that the circuit could produce the desired ECG waveforms by sending PWM outputs and low-pass filters and performing well [13]. Mohsin analyzed irrigation pump drivers by solar PV panels and the same time used the maximum power extracted in high light hours during the day by increasing the motor speed during the period and reducing it at low lighting periods by using PWM [14]. Kebir designed the construction of an inverter for a photovoltaic system. Buck-boost was supported by a photovoltaic panel using TL494, which generated a PWM signal for the control of two transistors to have a $311 \mathrm{~V}$ voltage adjusted by a control loop that held a constant voltage whatever influences temperature and sunlight [15].

Khan designed and manufactured digital MOSFET-based AVRs for synchronous generators to produce PWM, according to the peak voltage by the Peak detector [16]. Jasielski investigated the LBDD PWM hybrid modulator for BD-class digital audio amplifier based on the STM32F407VGT6 microcontroller and analog DLL. A new architecture and implementation of the 9-bit hybrid LBDD PWM modulator for Class-BD digital audio amplifiers had been proposed [17]. Ravi Kumar studied a microprocessorbased closed-loop speed control on DC motors using PWM. The benchmark goal of the DC drives was to maintain the system at a stable speed regardless of load conditions. In this project, the PWM used for DC motor speed control was generated using a P89V51RD2 microcontroller [18]. Ahmed investigated microcontroller-based rectifier design for chemical surface treatments. The microcontroller pulse width modulation (PWM) technology was used to produce DC currents that drive the h-bridge with $150 \mathrm{KHz}$. [19]. Liu designed high voltage DC power supplies using PWM wave microcontroller AT89S51 generated by using software programming as a helicopter control signal [20].

This research differs from previous researchers who examined Pulse Width Modulation (PWM) used for various applications such as PWM used for single phase induction motor voltage control, PWM for seven-stage one-phase inverters, PWM for drive gate converter circuits, and PWM for controlling motors DC This paper presents PWM to control the brightness and dim of the LED by using a visual net based on a microcontroller.

\section{LITERATURE REVIEW}

\section{A. LED}

Light Emitting Diode (LED) is an electronic component that emits monochromatic light when applied forward voltage [21]-[23]. It is a family of diodes made from semiconductor materials. The colors of the light emitted by the LED depend on the type of semiconductor material used. The LEDs can also emit infrared rays that are not visible as frequently encountered on TV remote control or remote control of other electronic devices.

An LED is small and easily attached to a variety of electronic devices [24]-[26] and has been widely used as a light in LCD TVs, replacing tube lights. Unlike an incandescent lamp, an LED does not require the burning of a filament so that it does not cause heat in producing light.

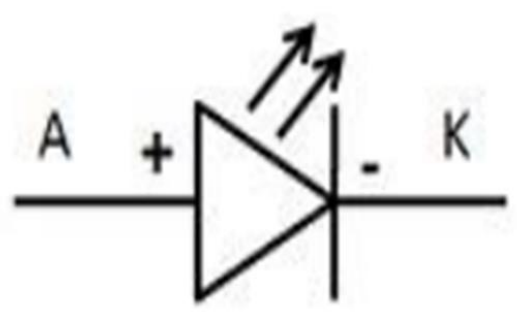

Fig. 1. The LED Symbol

The way an LED works is almost the same as the diode. It has two poles, namely the Positive pole $(\mathrm{P})$ and the Negative Pole (N) [27]-[30]. It will only emit light if the forward voltage is passed from the anode to the cathode. The LED consists of a semiconductor chip doped to create $\mathrm{P}$ and $\mathrm{N}$ junctions. The doping process in semiconductors is the process of adding impurity to a pure semiconductor to produce the desired electrical characteristics. When the LED is powered by a forward voltage or forward bias, i.e. from the anode $(\mathrm{P})$ to the cathode $(\mathrm{K})$, the excess electrons in the $\mathrm{N}$ type material will move to the region that has an excess hole (the hole), which is a positively charged region (P-Type material). When electrons meet the hole, they release photons and emit monochromatic light (one color). The LED, which emits light when flowing forward voltage, can also be classified as a transducer that can convert electrical energy into light energy.

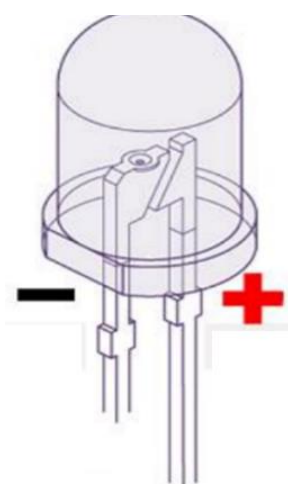

Fig. 2. LED Polarity

Figure 1 shows the polarity of Anode (+) and Cathode (-) terminals on the LED. The Anode terminal has longer legs 
and also smaller Lead Frames, while the Cathode terminal has shorter legs with a large Lead Frame and located on the flat side.

\section{B. Microcontroller}

A microcontroller is a digital electronic device that has input, output, and control with a program that can be written and deleted in a special way [7]. The microcontroller manages reading and writing data. There is a computer in the chip used to control electronic equipment, which emphasizes efficiency and cost-effectiveness. It is called a "small controller" where an electronic system that previously requires a lot of supporting components such as IC TTL and CMOS can be reduced, centralized, and controlled by the microcontroller.

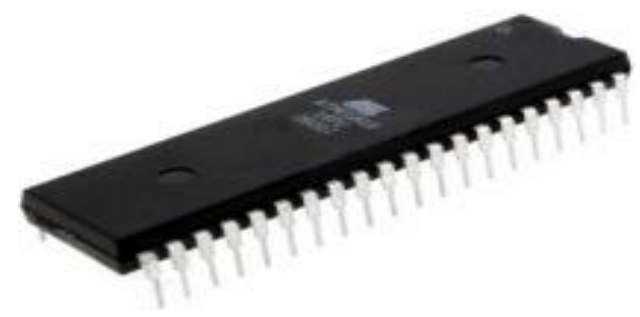

Fig. 3. Mikrokontroler ATMEGA 16

Using the microcontroller makes the electronic system concise, the design of electronic systems faster because most of the systems are easily modified software, and the search for interference is easier to trace. After all, the system is compact.

However, the microcontroller cannot completely reduce TTL and CMOS IC components frequently still needed for high-speed applications or simply increase the number of input and output (I/O) channels. In other words, a microcontroller is a mini or micro version of a computer since the microcontroller contains several peripherals that can be directly utilized, for example, parallel port, serial port, comparator, digital to analog conversion (DAC), analog to digital conversion, and so forth using uncomplicated or complex minimums systems.

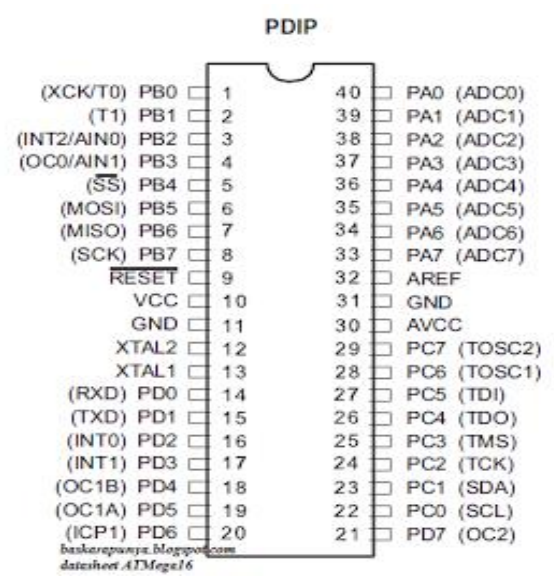

Fig. 4. AT Mega 16 Microcontroller PIN Configuration

AT Mega 16 is based on the RISC (Reduced Instruction Set Computing) architecture, where one instruction can be executed in one clock and reach 1 MPS (Milion Instruction Per Second) per MHz. An AVR microcontroller Atmega 16 has features compared to microcontroller types AT89C551, AT89C52, AT80S51, and AT89S52. The specialty is the Atmega 16, AVR microcontroller has eight channels 10 bit ADC input ports. The Atmega16 microcontroller has 40-foot pins with the following configuration.

The functions of each pin on the Atmega16 microcontroller are Port A (PAO ... 7) is a bidirectional input/output pin and ADC input pin. Port $\mathrm{B}$ (PAO ... 7) is a bidirectional input/output pin and a pin with special functions such as SPI, MISO, SS, AINI/OC0, AINO/INT2, T1, T0, and TI/XCK. Port C (PAO ... 7) is a bidirectional input/output pin and pins with special functions such as TOSC2, TOSC1, TDI, TDO, TMS, TCK, SDA, and SCL. Port D (PAO ... 7) is a two-way input/output pin and a pin with special functions such as RXD, TXD, INT0, INT1, OC1B, OC1A, and ICP1. $\mathrm{VCC}$ is a pin that functions as a power supply input. GND is a Ground pin. RESET is used to reset the microcontroller. XTAL1 and XTAL2 are external clock input pins. AVCC is a voltage input pin for the ADC. AREF is the ADC reference voltage input.

\section{Simplex Data Transmission}

One-way system (Simplex) is a communication system where the sender of the message only sends messages without having to receive a response from the recipient, meaning the sender continues to send messages regardless of whether the message was received or not. The application of this communication system is on the broadcast system of radio stations, television stations, and Static WEB [8].

One-way transmission or better known as simplex is a data transmission mode that can only carry data information in one direction, for example, radio and television. The signals sent from station transmitters can only be received by broadcast capture aircraft, but the broadcast capture aircraft cannot send information back to the transmitter station.

\section{$\begin{array}{lll}\text { Simplex } & \text { Transmitter } \longrightarrow \text { Receiver }\end{array}$}

Fig. 5. Simplex Transmission Mode

\section{Visual Net}

Visual Studio 2010 is a software used for the development of various applications that have various types, including desktop applications (Windows Form, CommandLine (Console), Web Applications, and Windows Mobile [9].

Visual Basic 2010 is one part of the latest programming product released by Microsoft, namely Microsoft Visual Studio 2010, released in April 2010. Visual Studio is a mainstay of programming products from Microsoft Corporation, in which it contains several types of IDE programming such as Visual Basic, Visual C\#, Visual $\mathrm{C}++$, Visual Web Developer, and Visual F\#.

Visual Basic 2010 is a version developed and improved from its predecessor version, Visual Basic 2008. Some of the development includes support for application development using Microsoft Silverlight, support for Cloud 
Computing-based applications, and extending support for databases both standalone or database server.

Visual Basic 2010 comes from a programming language that is very popular among computer programmers, namely BASIC, which was adopted by Microsoft in the Microsoft Quick BASIC program. Along with the development of computing and design technology, Microsoft released a product called Microsoft Visual Studio with Visual Basic in it.

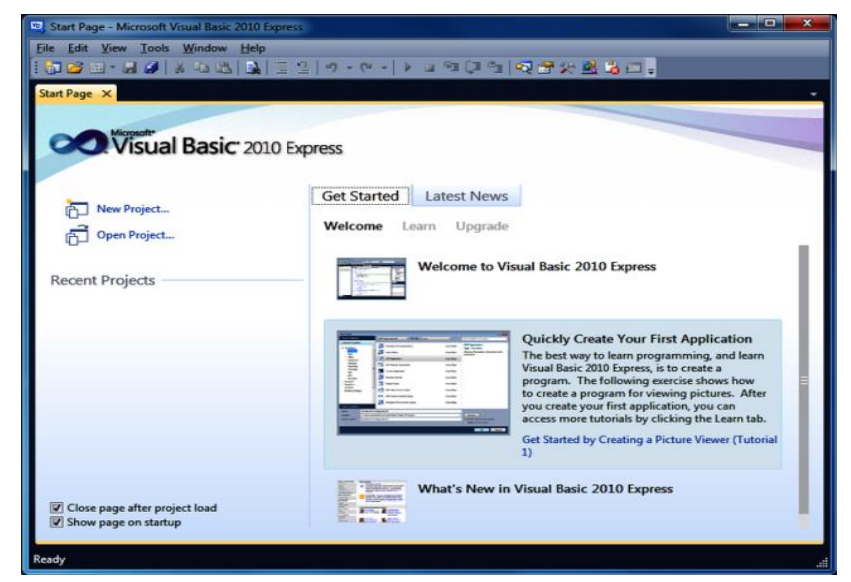

Fig. 6. Display Visual Studio 2010

\section{METHOD}

In conducting the research, the methodology was literature study needed to learn the basic theories related to the topic of discussion. The development processes integrated in the approach was tool design and manufacturing, tool analysis, discussion, and testing [10].

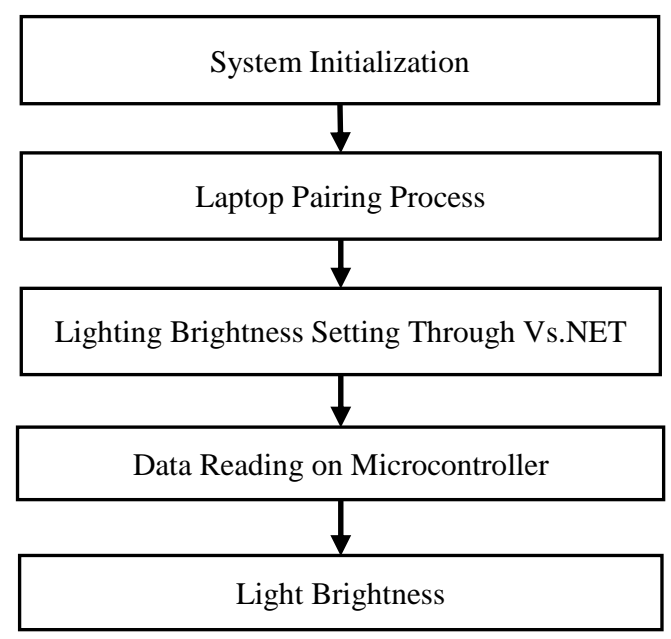

Fig. 7. System Algorithm

Figure 7 shows the system algorithm. System initialization was the process that occurred when the power supply was connected to the system when the data cable on the microcontroller was connected to the USB port on the laptop. The system would activate when the indicator LED on the microcontroller turned on [11]. A laptop pairing process with a microcontroller was a process to connect the laptop to the microcontroller to communicate with each other by entering the serial port using serial communication in which the data was sent in bytes. The final phase of the system was adjusting the brightness of the lights in the visual studio to increase or decrease it.

\section{RESULT AND DISCUSSION}

\section{A. Block Diagram}

The block diagram displayed in figure 8 illustrates the design of the input and output of the light brightness system. Ms. Visual Studio worked as an input. A microcontroller as a processing unit was connected to a $12 \mathrm{~V}$ power supply. Visual Basic served to display the distance interface, and Visual Net to display the distance of the objects to the screen.

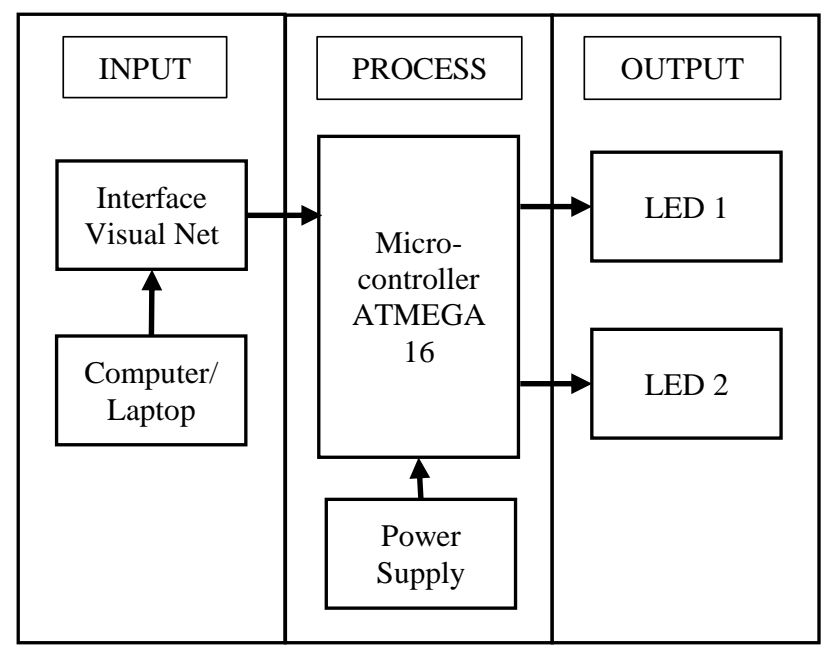

Fig. 8. Block Diagram

\section{B. Physical Design of the Tool}

In this case, the physical design of the tool was: sketch of the warning system on vehicles passing into sharp turns using Google Sketch up software, while the sketch of the tool design system is as follows:

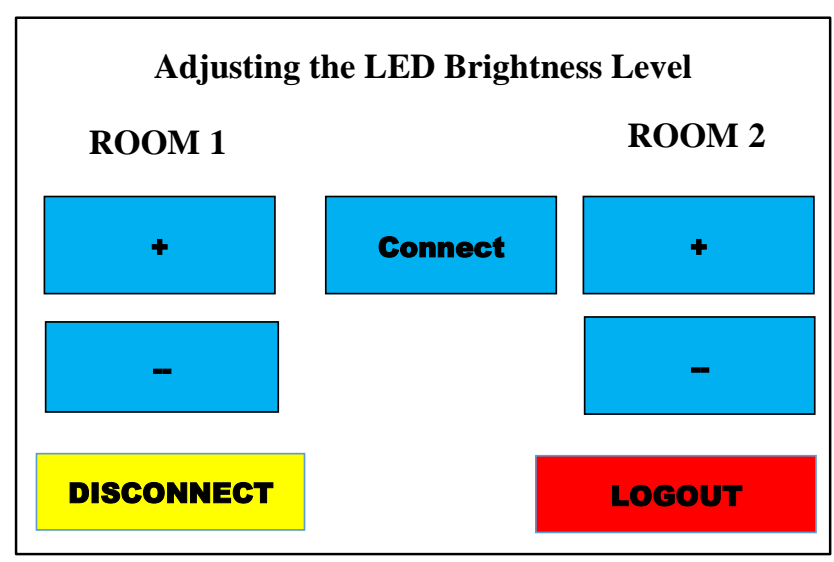

Fig. 9. Visual Net Interface Design

In the picture above is the design of the whole system at the time of implementation. Visual studio used is visual studio 2010 and laptop and is connected to the laptop with a data cable via a USB port. The components needed in making the system are shown in Table 1. 
TABLE I. COMPONENTS TO BE USED

\begin{tabular}{|l|l|l|}
\hline No & Nama & Numbers \\
\hline 1 & Microcontroller AVR Atmega 16 & 1 \\
\hline 2 & Downloader cable & 1 \\
\hline 3 & LED & 2 \\
\hline 4 & Resistor $330 \Omega$ & 2 \\
\hline 5 & USB TTL & 1 \\
\hline
\end{tabular}

\section{Pulse Width Modulation Value}

The Pulse Width Modulation value in this system uses 8 bit resolution (255), which means that each speed value is represented by the numbers 0 to 255 . The following Pulse Width Modulation values will be implemented on the system:

Duty cycle $0 \%$

PWM = Duty Cycle $\mathrm{x}$ PWM Resolution Value

$\mathrm{PWM}=0 \% \times 255$

$\mathrm{PWM}=0$

When the duty cycle was $0 \%$ and the resolution used was 8 bits, the value of the duty cycle was represented by numbers 0 to 255 to generate a PWM value of 0 .

Duty cycle $40 \%$

PWM = Duty Cycle $\mathrm{x}$ PWM Resolution Value

$\mathrm{PWM}=40 \% \times 255$

$\mathrm{PWM}=102$

When the duty cycle was $40 \%$ and the resolution used was 8 bytes, the value of the duty cycle was represented by numbers 0 to 255 to generate a PWM value of 102 .

Duty cycle $65 \%$

PWM = Duty Cycle $\mathrm{x}$ PWM Resolution Value

$\mathrm{PWM}=65 \% \times 255$

$\mathrm{PWM}=165,75$

When the duty cycle was $65 \%$ and the resolution used was 8 bytes, the value of the duty cycle was represented by numbers 0 to 255 to generate the PWM value of 165.75 .

Duty Cycle $90 \%$

PWM = Duty Cycle $x$ PWM Resolution Value

$\mathrm{PWM}=90 \% \times 255$

$\mathrm{PWM}=229.50$

When the duty cycle was $90 \%$ and the resolution used was 8 bytes, the value of the duty cycle was represented by numbers 0 to 255 to generate the PWM value of 229.50 .

\section{ATMegal6 Minimum System Series16}

The microcontroller used for the design was AVR type, namely ATMega16, programmed using BASCOM-AVR Software.

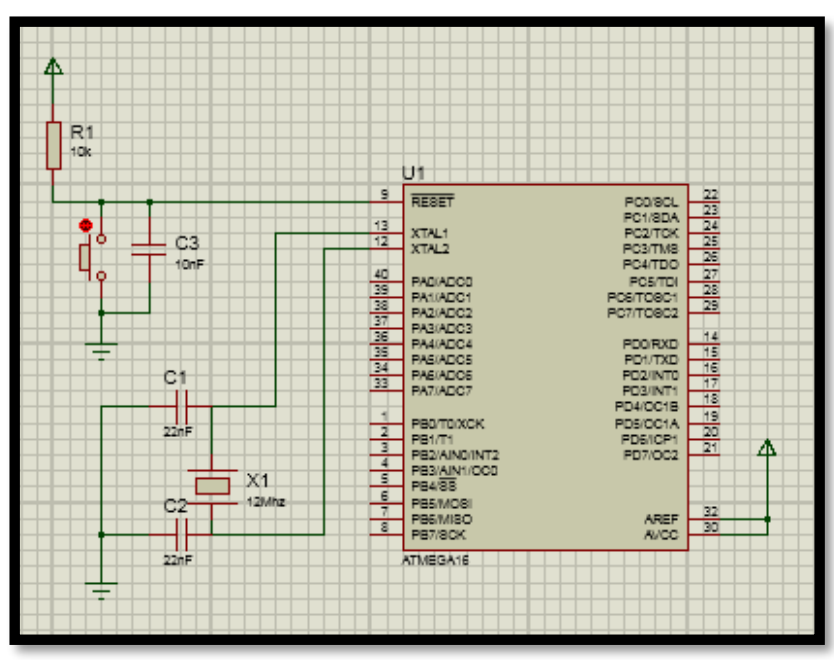

Fig. 10. ATMega16 Minimum System Series 16

\section{E. Overall Series of Electronic Schematics}

In the system that was made the design of the prototype system was made in 2 LEDs using 220 ohm resistors and $16 * 2$ LCD to find out the value of pwm. Next is a series of LEDs and resistors from the system being built.

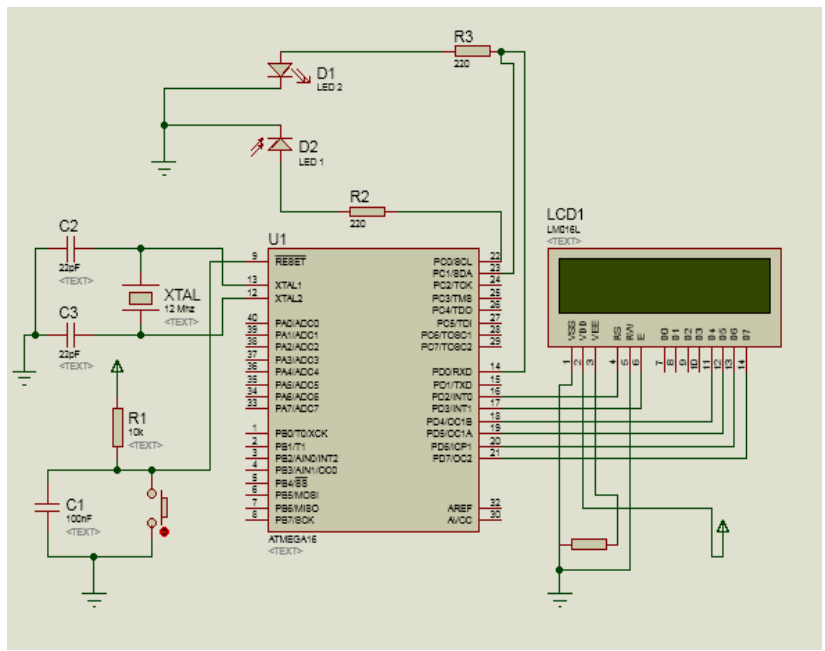

Fig. 11. Overall System Series

The design of the prototype system was made with two LEDs utilizing two 220-ohm resistors and 16x2 LCD to find out the PWM value. Subsequently, a series of LEDs and resistors of the system was built.

\section{F. Testing}

Testing was conducted to examine whether the design applied to the tool worked successfully or not. The VB form design had two rooms prototypes. Two buttons indicating plus and minus were available to adjust the level of light in the room, there were several buttons. Figure 12 shows the VB display.

Visual Studio Net managed to adjust the brightness of the lights by first connecting the serial port that matched with the one on the device manager display. After the pairing process, direct light brightness control could be controlled manually. 


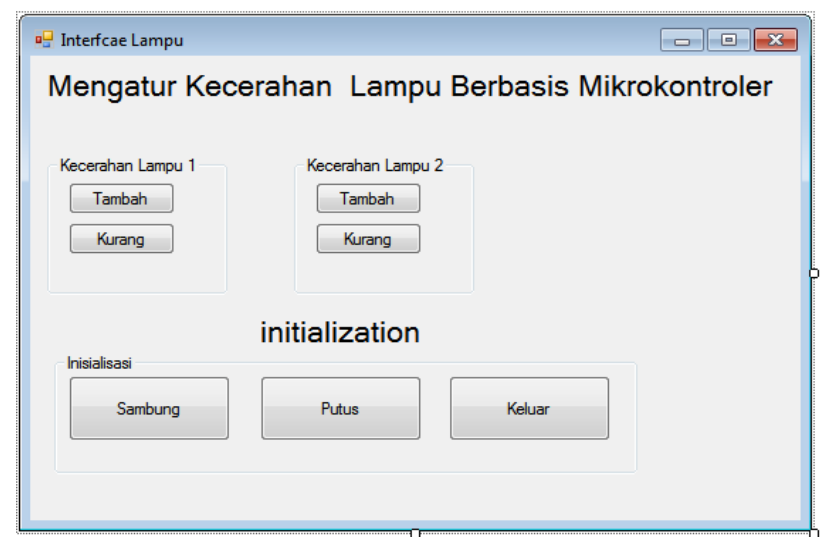

Fig. 12. Visual Basic display

\section{Testing on WM Values on LCD and Lamp Brightness}

The LCD testing was carried out by connecting the LCD to a microcontroller containing a program to display the PWM value to be processed. After testing, it would be found whether the LCD had worked properly and according to what was designed. Figure 13 shows the display of the PWM value on the LCD.
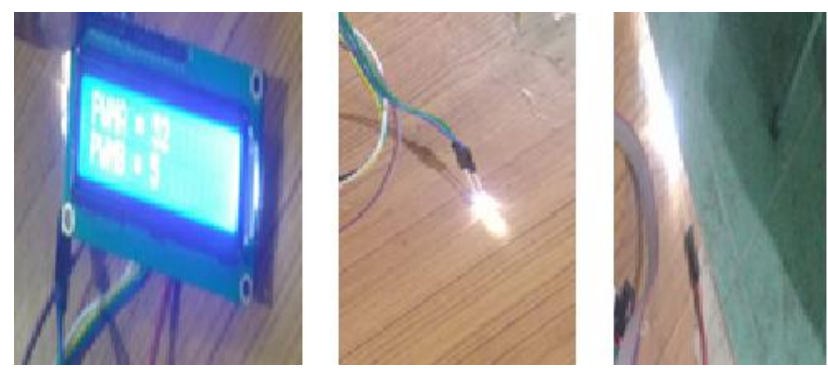

Fig. 13. Testing Lights \& LCD

\section{Voltage Testing}

Voltage test is needed to find out whether the components used are working. The voltage test is shown in table 2. From the table it can be seen that the microcontroller works at a voltage of 4.98 Volt, the LED can light up when the voltage condition is 3 volts and the LCD works with a voltage of 4.98 Volt

TABLE II. Voltage Testing

\begin{tabular}{|l|l|l|l|}
\hline \multirow{2}{*}{ No. } & \multirow{2}{*}{ Component Name } & Situation & Component Volt \\
\hline \multirow{2}{*}{1} & \multirow{2}{*}{ Microcontroller } & On & 4,98 Volt \\
\cline { 3 - 4 } & & Off & 0.02 Volt \\
\hline \multirow{2}{*}{2} & \multirow{2}{*}{ LED } & Detected & 3 Volt \\
\cline { 3 - 4 } & & Not detected & 0.02 Volt \\
\hline 3 & \multirow{2}{*}{ LCD } & On & 4,97 Volt \\
\cline { 3 - 4 } & & Off & 0.02 Volt \\
\hline
\end{tabular}

\section{System Strengths and Weaknesses}

Based on the exposure and experiments conducted, the author found the advantages and disadvantages of the design of the microcontroller-based light brightness. The advantages were 1). the process of adjusting the light through the interface display, 2). the process of lamp brightness through the PWM value, and 3). the changes in the PWM value displayed on the LCD. Meanwhile, the disadvantages were 1). the manual lighting settings and 2). the challenging process of laying down components.

\section{CONCLUSION}

The conclusions in this study are as follows. The application of the Avr16 microcontroller based Pulse Width Modulation (PWM) technique on the automatic control system can effectively adjust the brightness of the light to be ideal under the conditions we want. Implementation of design and construction using visual basic net with prototype 2 rooms can make it easier to control the level of light through the plus and less buttons.

\section{REFERENCES}

[1] G. Zigirkas and J. Kalomiros, "Voltage control of single-phase induction motors using asymmetrical PWM and fuzzy logic," in 2016 5th International Conference on Modern Circuits and Systems Technologies (MOCAST), 2016, pp. 1-4.

[2] S. A. Zulkifli, F. N. F. Ramli, and S. Razali, "Undergraduate student experience in development of ZVS power converter for voltage control with low cost microcontroller," in 2016 IEEE International Conference on Automatic Control and Intelligent Systems (I2CACIS), 2016, no. October, pp. 55-60.

[3] R. R. Shaikh and J. R. Rana, "Single phase seven level inverter," in 2016 International Conference on Energy Efficient Technologies for Sustainability (ICEETS), 2016, no. Mli, pp. 306-310.

[4] V. Ravindran and J. Sutaria, "Implementation in arm microcontroller to maximize the power output of solar panel using Hill Climbing Algorithm," in 2016 International Conference on Electrical, Electronics, and Optimization Techniques (ICEEOT), 2016, pp. 1234-1240.

[5] Z. Xu and Y. Kang, "PWM speed DC motor drive power design," in 2016 31st Youth Academic Annual Conference of Chinese Association of Automation (YAC), 2016, pp. 419-423.

[6] L. P. D. Silva et al., "Low-cost didactic module for single-phase inverter teaching," in 2017 Brazilian Power Electronics Conference (COBEP), 2017, vol. 12, no. 2, pp. 1-6.

[7] R. Guedouani, B. Fiala, and M. S. Boucherit, "Implementation of multi-carrier PWM using a DSP TMS320F28335. Application to series multicellular single-phase inverter," in 2017 10th International Conference on Electrical and Electronics Engineering (ELECO), 2017, pp. 1424-1429.

[8] D. Savkin, A. Anuchin, V. Kulmanov, Y. Vagapov, and I. Gulyaev, "Real-time model of switched reluctance drive based on a LUT magnetization curve for educational purposes," in 2017 15th International Conference on Electrical Machines, Drives and Power Systems (ELMA), 2017, pp. 480-483.

[9] Shivesh, R. Mishra, and E. A. Elisabeth, "Speed control of ceiling fan using PWM technique," in 2017 International Conference on Computation of Power, Energy Information and Commuincation (ICCPEIC), 2017, vol. 2018-Janua, pp. 686-690.

[10] H. Bolanos-Cerrud, A. Martinez-Sibaja, J. P. Rodriguez-Jarquin, K. Romero-Guizasola, I. Herrera-Aguilar, and R. Posada-Gomez, "Optimization algorithm for accurate frequency sine wave PWM generation with microcontrollers," in 2017 14th International Conference on Electrical Engineering, Computing Science and Automatic Control (CCE), 2017, pp. 1-6.

[11] M. Aref, I. Ahmed, V. Oboskalov, A. Mahnitko, and A. Gavrilovs, "Microcontroller Look-up Table of Digital Control MPPT of PV System," in 2018 IEEE 59th International Scientific Conference on 
Power and Electrical Engineering of Riga Technical University (RTUCON), 2018, pp. 1-5.

[12] M. Pimentel, Y. Alejaldre, A. Avalos, and J. Cerda, "A HIL-based DC Motor Speed Control," in 2018 IEEE International Autumn Meeting on Power, Electronics and Computing (ROPEC), 2018, no. Ropec, pp. 1-5.

[13] S. C. Yener and R. Mutlu, "A microcontroller-based ECG signal generator design utilizing microcontroller PWM output and experimental ECG data," in 2018 Electric Electronics, Computer Science, Biomedical Engineerings' Meeting (EBBT), 2018, pp. 14.

[14] A. T. Mohsin and I. M. Abdulbaqi, "Analysis of an Irrigation Pump Driver Fed by Solar PV Panels (Part II)," in 2018 International Conference on Engineering Technology and their Applications (IICETA), 2018, no. Part II, pp. 1-6.

[15] A. El Kebir, H. Belhadj, K. Negadi, and A. B. Bey, "Design and Construction of an Inverter for a Photovoltaic System," in 2018 IEEE XXVII International Scientific Conference Electronics - ET, 2018, pp. $1-4$.

[16] I. A. Khan, Y. Xu, and B. Tahir, "Design and manufacturing of digital MOSFET based-AVR for synchronous generator," in 2015 IEEE International Conference on Cyber Technology in Automation, Control, and Intelligent Systems (CYBER), 2015, pp. $217-222$.

[17] J. Jasielski, S. Kuta, W. Kolodziejski, and W. Machowski, "Hybrid LBDD PWM modulator for digital class-BD audio amplifier based on STM32F407VGT6 microcontroller and analog DLL," in 2015 22nd International Conference Mixed Design of Integrated Circuits \& Systems (MIXDES), 2015, pp. 556-561.

[18] K. . Ravi Kumar, Jaideep, Rohit, and Vikas, "Microprocessor based closed loop speed control of DC motor using PWM," in 2015 International Conference on Control, Instrumentation, Communication and Computational Technologies (ICCICCT), 2015, vol. 2, pp. 255-257.

[19] A. A. A. Ahmed, E. E. E. Omer, A. M. E. Ahmed, and A. A. H. Elnazir, "Microcontroller based design of rectifier for chemical surface treatment," in 2015 International Conference on Computing, Control, Networking, Electronics and Embedded Systems Engineering (ICCNEEE), 2015, pp. 162-167.

[20] J. Liu and Z. Dong, "A design for high voltage DC power supply," in 2015 5th International Conference on Electric Utility Deregulation and Restructuring and Power Technologies (DRPT), 2015, pp. 2227-2231.
[21] A. Hodzic and E. Mujcic, "Teleoperation system control based on the method for supervisory control with variable time delay," in 2015 23rd Telecommunications Forum Telfor (TELFOR), 2015, pp. 345-348.

[22] S. P. Preejith, A. Alex, J. Joseph, and M. Sivaprakasam, "Design, development and clinical validation of a wrist-based optical heart rate monitor," in 2016 IEEE International Symposium on Medical Measurements and Applications (MeMeA), 2016, pp. 1-6.

[23] Y. S. Yang and H. C. Kim, "Development of a miniaturized IV drip rate meter using optical sensors and fuzzy rule based detection algorithm," in Proceedings of the 20th Annual International Conference of the IEEE Engineering in Medicine and Biology Society. Vol.20 Biomedical Engineering Towards the Year 2000 and Beyond (Cat. No.98CH36286), 1998, vol. 4, no. 4, pp. 17951798.

[24] S. A. Daud, S. S. Mohd Sobani, M. H. Ramiee, N. H. Mahmood, P. L. Leow, and F. K. Che Harun, "Application of Infrared sensor for shape detection," in 2013 IEEE 4th International Conference on Photonics (ICP), 2013, pp. 145-147.

[25] Molla Shahadat Hossain Lipu, Tahia Fahrin Karim, Md. Lushanur Rahman, and F. Sultana, "Wireless security control system \&amp; sensor network for smoke \&amp; fire detection," in 2010 IEEE International Conference on Advanced Management Science(ICAMS 2010), 2010, vol. 3, pp. 153-157.

[26] T. Ruytenberg, A. G. Webb, and J. W. M. Beenakker, "A multipurpose open-source triggering platform for magnetic resonance," $J$. Magn. Reson., vol. 247, pp. 15-21, Oct. 2014.

[27] A. Bhaskar, "EyeAwake: A cost effective drowsy driver alert and vehicle correction system," in 2017 International Conference on Innovations in Information, Embedded and Communication Systems (ICIIECS), 2017, pp. 1-6.

[28] T. Adiono, M. Y. Fathany, S. Feranti Anindya, S. Fuada, and I. G. Purwanda, "Wirelessly Control for RGB Lamp End-device: Design and Implementation," in TENCON 2018 - 2018 IEEE Region 10 Conference, 2018, no. October, pp. 2066-2070.

[29] M. A. Yusof and Y. Wen Hau, "Mini Home-Based Vital Sign Monitor with Android Mobile Application (myVitalGear)," in 2018 IEEE-EMBS Conference on Biomedical Engineering and Sciences (IECBES), 2018, pp. 150-155.

[30] N. Prabhu, D. Naik, G. . Prashanth, and S. Mikkili, "Smart Energy Auditing using GSM and Fuzzy Logic Controller based Power Quality Management," in 2018 International Conference on Smart City and Emerging Technology (ICSCET), 2018, pp. 1-6. 